\title{
SIT führt hierzulande ein Schattendasein
}

\author{
Wie es um die Versorgung von Patienten mit allergischer Rhinitis in \\ Deutschland bestellt ist, haben Mediziner der Technischen Universität \\ Dresden untersucht. Sie stießen auf Defizite und einige Luft nach oben.
}

—ür eine Versorgungsstudie nutzten - Dresdner Forscher die Daten von gut 1,8 Millionen Versicherten der AOK Plus, deren Mitglieder aus Sachsen und Thüringen stammen. Die Prävalenz der allergischen Rhinitis (AR) betrug laut den ICD-10-Diagnosen der AOK-Versicherten $6,6 \%$ in den Jahren 2005 und 2006. Weitere 3,3\% erhielten in den Jahren 2007 bis 2011 eine AR-Erstdiagnose. $30,6 \%$ respektive 19,7\% der Patienten mit AR waren an Asthma oder atopischer Dermatitis erkrankt. Die Rate lag damit achtmal (Asthma) und viermal (atopische Dermatitis) so hoch wie jene von Patienten ohne AR.

Auffällig war auch das erhöhte Risiko von AR-Patienten für psychische Störungen. So war das Risiko für Depressionen um gut $60 \%$, für Angststörungen um
$50 \%$ und für Aufmerksamkeitsdefizit-/ Hyperaktivitätsstörung um $20 \%$ erhöht.

An der Behandlung der Patienten waren mehrere Facharztrichtungen beteiligt. $21 \%$ respektive $32 \%$ der pädiatrischen oder der erwachsenen Patienten wurden bei einem HNO-Arzt vorstellig. Dermatologen waren in die Therapie von $9 \%$ und $16 \%$ der Patienten involviert. Eine ausschließlich allgemeinärztliche Behandlung wurde $20 \%$ und $36 \%$ der AR-Patienten zuteil.

Mindestens eine Verordnung für nicht sedative Antihistaminika erhielten 36\% der Patienten mit AR. Sedierende Präparate aus dieser Substanzgruppe standen bei 5,3\% aufdem Rezept. Antihistaminika sind in Deutschland allerdings frei verkäuflich und diese Zahlen daher mit Vorsicht $\mathrm{zu}$ interpretieren. Über die Ver- schreibung von Glukokortikoid-Nasensprays finden sich keine Angaben.

Gut $16 \%$ der AR-Patienten wurden einer spezifischen Immuntherapie unterzogen, wobei es sich in rund $80 \%$ der Fälle und damit weit überwiegend um die subkutane Applikationsform handelte. Die sublinguale Anwendung lag deutlich dahinter, mit $11 \%$ für die Anwendung von Tropfen und $3 \%$ für die Gabe von Tabletten.

Fazit: Die Autoren finden es überraschend, dass die kausale Therapie der AR verhältnismäßig selten angewendet wird. Schließlich gebe es nicht viele chronische Leiden, die sich kausal behandeln ließen. Die AR gehöre dazu. Insgesamt sei angesichts der Prävalenz- und Inzidenzzahlen von einer erheblichen AR-bedingten Krankheitslast in Deutschland auszugehen, nicht zuletzt mit Blick auf psychische Erkrankungen. Dr. Robert Bublak

Schmitt J et al. Medical care and treatment of allergic rhinitis: a population-based cohort study based on routine healthcare utilization data. Allergy 2016;71:850-8

\section{Epigenetik beeinflusst Allergie und Toleranz}

Neben dem Erbgut und Umwelteinflüssen spielt eine dritte Kraft eine Rolle bei der Entwicklung von Allergien: die Epigenetik. Auch für die Toleranzinduktion scheint sie wichtig zu sein.

Z $\mathrm{u}$ den epigenetische Vorgängen zählen Veränderungen der Genfunktion, die nicht auf Mutation beruhen. Dabei geht es um die Regulation der Transkription und demzufolge um die Verfügbarkeit und den Gebrauch genetischer Information. Drei Mechanismen stehen im Vordergrund: die Modifikation von Histonen, die posttransskriptionale Modifikation durch Mikro-RNA (miRNA) oder „small interfering RNA“ (siRNA) und die DNA-Methylierung. Mit den Einflüssen der Epigenetik auf Allergieentstehung und Toleranzentwicklung hat sich Michael Kabesch befasst. Er betont dabei die zentrale Position epigenetischer Prozesse in der Immunregulation, weil sie eine rasche Anpassung an Gefahrensignale und ein $\mathrm{Ab}$ und Anschalten von Reaktionswegen in einer zellspezifischen, fein ausbalancierten Weise erlauben.

Epigenetische Signaturen sind laut Kabesch an sämtlichen Aspekten des Allergiegeschehens beteiligt. Mit ihnen lassen sich Individuen identifizieren, die allergieanfällig sind, noch bevor die Erkrankung symptomatisch wird; die Signaturen sind mit allergischen Erkrankungen assoziiert; und sie stehen auch in Zusammenhang mit der erfolgreichen Induktion von Toleranz.

Bestimmte DNA-Methylierungsmuster sind beispielsweise typisch für Gene, die für IL4- und IL5-Rezeptoren kodieren und die schon früher mit Allergien und IgE-Spiegeln in Verbindung gebracht wurden. Über die Methylierung lässt sich ein bedeutend größerer Anteil der IgE-Varianz in der Bevölkerung er- klären als mit den EinzelnukleotidPolymorphismen, die mit IgE zusammenhängen.

Unterschiede im Methylierungsmuster sind etwa bei Patienten mit atopischer Dermatitis und bei Patienten mit Asthma gefunden worden, jeweils im Vergleich zu gesunden Kontrollpersonen.

Allergologisch interessant an den epigenetischen Vorgängen ist ihre prinzipielle Reversibilität. Kabesch hält es für möglich, dass diese Eigenschaft als Schlüssel für die Induktion von Toleranz, damit für die Umkehrung der allergischen Reaktion und eine echte Heilung von Allergien dienen könnte. Dass epigenetische Mechanismen manipulierbar sind, zeigen beispielsweise Studien zur Immuntherapie von Erdnussallergie.

Das lässt auf neue Therapien hoffen. Manche epigenetischen Modifikatoren, und zwar durchaus starke, sind ohnehin schon längst im Einsatz: Glukokortikoide. Allerdings setzen sie ungezielt an. Entwickelt werden sollen Möglichkeiten zur zielgenauen Manipulation, so wie die $\mathrm{Na}$ - 